\title{
Potential of airborne lidar measurements for cirrus cloud studies
}

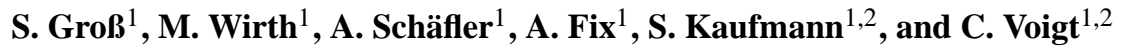 \\ ${ }^{1}$ Institut für Physik der Atmosphäre, Deutsches Zentrum für Luft- und Raumfahrt (DLR), Oberpfaffenhofen, \\ 82234 Wessling, Germany \\ ${ }^{2}$ Johannes-Gutenberg-Universität Mainz, Institut für Physik der Atmosphäre, 55122 Mainz, Germany
}

Correspondence to: S. Groß (silke.gross@ dlr.de)

Received: 17 February 2014 - Published in Atmos. Meas. Tech. Discuss.: 16 April 2014

Revised: 9 July 2014 - Accepted: 23 July 2014 - Published: 26 August 2014

\begin{abstract}
Aerosol and water vapour measurements were performed with the lidar system WALES of Deutsches Zentrum für Luft- und Raumfahrt (DLR) in October and November 2010 during the first mission with the new German research aircraft G55-HALO. Curtains composed of lidar profiles beneath the aircraft show the vertical and horizontal distribution and variability of water vapour mixing ratio and backscatter ratio above Germany. Two missions on 3 and 4 November 2010 were selected to derive the water vapour mixing ratio inside cirrus clouds from the lidar instrument. A good agreement was found with in situ observations performed on a second research aircraft flying below HALO. ECMWF analysis temperature data are used to derive relative humidity fields with respect to ice (RHi) inside and outside of cirrus clouds from the lidar water vapour observations. The RHi variability is dominated by small-scale fluctuations in the water vapour fields while the temperature variation has a minor impact. The most frequent in-cloud RHi value from lidar observations is $98 \%$. The RHi variance is smaller inside the cirrus than outside of the cloud. 2-D histograms of relative humidity and backscatter ratio show significant differences for in-cloud and out-of-cloud situations for two different cirrus cloud regimes. Combined with accurate temperature measurements, the lidar observations have a great potential for detailed statistical cirrus cloud and related humidity studies.
\end{abstract}

\section{Introduction}

Although clouds have an important impact on the Earth's atmosphere and climate system (Cox, 1971; Liou, 1986) their influence on the Earth's radiation budget is still hard to determine (IPCC, 2007, 2013). Especially, radiative effects of cirrus clouds are a major uncertainty for determination of the cloud feedback factor in climate response. Typically, they are assumed to have a net warming effect (Chen et al., 2000). Radiative properties of mid-latitude cirrus clouds strongly depend on their microphysical parameters, e.g. ice crystal shape, size distribution and number concentration (Stephens et al., 1990; Haag and Kärcher, 2004; Fusina et al., 2007), which are influenced by ambient conditions, especially dynamics (Kärcher and Lohmann, 2003), temperature and supersaturation (Heymsfield, 1977; Khvorostyanov and Sassen, 1998b) as well as the nucleation mode, i.e. the composition of the ambient aerosol (e.g. Ström and Ohlsson, 1998; Seifert et al., 2004). Furthermore, small-scale turbulence is important for the fine structure of cirrus clouds, which affects the inhomogeneity of microphysical properties ( $\mathrm{Gu}$ and Liou, 2000) and therefore of the cirrus' radiative effect (Liou, 1972). The inhomogeneous nature of cirrus on different spatial scales is one major issue which complicates modelling of their radiative properties. Model simulations usually use idealized cloud structure and microphysics, as well as radiative transfer approximations. To improve the representation of cirrus clouds in simulations and circulation models, we need a better understanding of the micro- and macrophysical properties of cirrus clouds, as well as of small-scale processes within cirrus.

Airborne Differential Absorption Lidar (DIAL) measurements of water vapour (Ehret et al., 1993; Bösenberg, 1998; Browell et al., 1998) provide 2-D information of the atmospheric structure, and are thus a suitable tool to study the fine structure of cirrus clouds, as well as their macrophysical properties. The combination of DIAL water vapour measurements with additional temperature information (e.g. 
from model analyses or dropsondes) further enables us to investigate the variability of relative humidity and ice supersaturation within cirrus clouds which are crucial properties for cirrus cloud evolution (e.g. Heymsfield and Miloshevich, 1995). However, up to now, the high signal dynamics within clouds limited the use of airborne downward-looking DIAL measurements for mid-latitude cirrus clouds. An optimal distance of about $2 \mathrm{~km}$ to the cirrus cloud is required to avoid an overload of detectors and data acquisition due to the immense signal dynamics in the near field resulting from the $r$ dependence of the backscatter signal. Up to now the required flight altitude to examine mid-latitude cirrus clouds up to about $13 \mathrm{~km}$ height was only accessible with highaltitude aircraft like the Russian stratospheric aircraft Geophysica (Stefanutti et al., 1999) and the NASA ER-2. With the new German research aircraft HALO (High Altitude and LOng range) (Krautstrunk and Giez, 2012) it is possible to reach flight altitudes of up to $15 \mathrm{~km}$, and thus a sufficient distance to the cirrus cloud top in most cases.

For the first time, measurements of the airborne aerosol and water vapour DIAL WALES (Water vapour Lidar Experiment in Space; Wirth et al., 2009), operated onboard HALO during its first scientific mission (Techno-Mission) are presented. The HALO Techno-Mission took place in October and November 2010 and provided the opportunity to investigate cloud properties with two different aircraft. HALO, flying at a cruise altitude of $\sim 14 \mathrm{~km}$ probed the cloud $(\sim 1 \mathrm{~km}$ below cruise altitude) with the lidar. Additionally, the DLR research aircraft Falcon was equipped with in situ instruments to measure temperature and water vapour mixing ratio within cirrus clouds. This unique combination of these two aircraft provided the opportunity to compare the different measurement strategies, i.e. in situ and remote sensing measurements with a focus on cirrus cloud studies. Relative humidity with respect to ice (RHi) is determined within the cirrus clouds based on the novel high-altitude DIAL observations combined with ECMWF model analysis temperature data.

Section 2 gives an overview over the aircraft and mission design, the WALES system, and the WARAN in situ hygrometer onboard the Falcon used for water vapour intercomparison. Section 3 demonstrates the potential of the DIAL system for cirrus cloud studies based on a case study with measurements inside the cirrus cloud. Section 4 provides a summary and discussion of the main findings. Section 5 gives an outlook to future cirrus cloud observations with remote sensing instruments onboard HALO.

\section{Data and methods}

\subsection{HALO and Techno-Mission}

HALO (Fig. 1) is a modified Gulfstream G550 business jet operated by the flight department of DLR in
Table 1. Technical features of Gulfstream G550 HALO aircraft adopted from Krautstrunk and Giez (2012).

\begin{tabular}{ll}
\hline Engine & Rolls-Royce BR710 \\
\hline Aircraft Performance & \\
\hline Maximum range & $12500 \mathrm{~km}$ \\
Maximum cruise altitude & $15540 \mathrm{~m}$ \\
Take-off distance & $1801 \mathrm{~m}$ \\
Maximum speed & $0.885 \mathrm{Mach}$ \\
\hline Weights & \\
\hline Maximum take-off weight & $41277 \mathrm{~kg}$ \\
Maximum payload & $3 \mathrm{t}$ \\
\hline Exterior & \\
\hline Length & $29.4 \mathrm{~m}$ \\
Height & $7.9 \mathrm{~m}$ \\
Wingspan & $28.5 \mathrm{~m}$ \\
\hline Interior & \\
\hline Cabin length & $15.3 \mathrm{~m}$ \\
Cabin height & $1.88 \mathrm{~m}$ \\
Cabin width & $2.24 \mathrm{~m}$ \\
Cabin volume & $47.3 \mathrm{~m}^{3}$ \\
\hline
\end{tabular}

Oberpfaffenhofen. With a range of more than $8000 \mathrm{~km}$ and an endurance of up to more than 10 flight hours even large-scale atmospheric features can be investigated at almost all regions around the globe. A maximum cruising altitude of more than $15 \mathrm{~km}$ enables measurements in the upper troposphere and lower stratosphere in high- and mid-latitude regions. With a payload of up to three tons, HALO provides enough capacity to accommodate a synergetic payload to collect a comprehensive atmospheric data set (Krautstrunk and Giez, 2012). Technical details can be found in Table 1 .

In the course of the first scientific HALO mission, the so-called Techno-Mission, five flights with HALO aircraft were performed from 28 October to 5 November 2010 out of Oberpfaffenhofen, Germany. The major part of the flights took place in the Temporary Reserved Airspaces (TRA, i.e. military areas with restricted access for commercial aircraft) Allgäu in southern Germany and Mecklenburg-Vorpommern in northeastern Germany (28 October to 29 October and 5 November 2010). Here we present data of the flights on 3 November (from 09:51 to 13:17 UTC) and 4 November (10:21 to 13:32 UTC), 2010. Lidar observations were only possible inside the TRA areas. The 4 November flight data between 10:47 and 11:54 UTC are used for the comparison of remote sensing (lidar) data and in situ data of the Falcon flying beneath. The measurement situation was characterized by a stationary cirrus cloud covering the whole measurement area. Data from 3 November (10:15 to 11:25 UTC) are used to compare the RHi statistics in a different cloud regime characterized by a transient cirrus cloud drifting out 


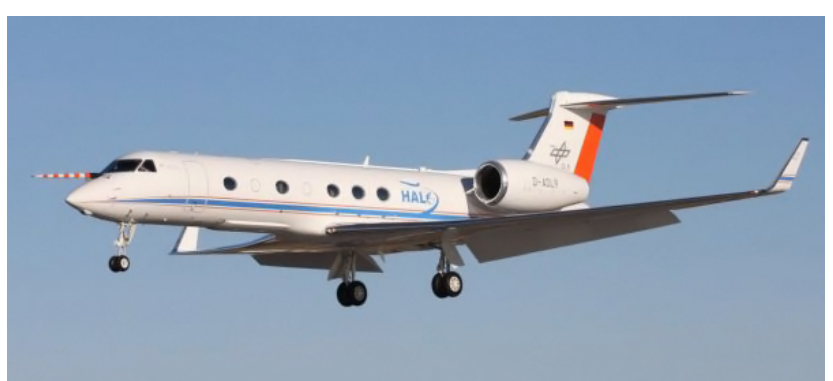

Figure 1. HALO (High Altitude and LOng range) aircraft. Photo adopted from http://www.halo.dlr.de/.

of the measurement area. This gave us the opportunity to perform measurements in cloudy and in cloud-free air masses. HALO was equipped with a spectrometer system operated by University of Leipzig together with an instrument for measuring the actinic flux in cooperation with Forschungszentrum Jülich (HALO-SR) (Fricke et al., 2014), an automated high-volume air sampling system (MIRAH - Measurements of Stable Isotope Ratios in Atmospheric Trace Gases on HALO) of University of Wuppertal (Krebsbach et al., 2013), and an ion trap mass spectrometer of DLR (Roiger et al., 2011). Additionally, and in the focus of this paper, the DIAL system WALES (Wirth et al., 2009) was provided by DLR Institute of Atmospheric Physics (IPA). The campaign focused on the test of the in-flight performance of new instrumentation and validation of remote sensing instruments with in situ measurements. A further aim was the development and evaluation of new sampling strategies for future campaigns, including finding an optimal flight level for remote cloud studies as well as to investigate the possibility to use HALO as the pathfinder for a secondary aircraft with an in situ payload for cloud studies (e.g. distance from cloud top). For intercomparison and validation, the DLR Falcon was equipped with several in situ instruments including the WARAN tuneable diode laser hygrometer operated by DLR (Voigt et al., 2014). Falcon flew in parallel, either wing by wing to compare in situ instruments or several kilometres below HALO to compare lidar with in situ measurements.

\subsection{Differential absorption lidar WALES}

Differential absorption lidar is an active remote sensing technique for measuring atmospheric gases such as water vapour (e.g. Bösenberg, 1998; Browell et al., 1998). It is based on the absorption at different laser wavelengths with narrow spectra. The so-called online wavelength is centred on a molecular water vapour absorption line. For the offline wavelength a non-absorbing wavelength is used, which serves as the reference. By calculating the difference between absorptions at online and offline wavelength, a profile of the water vapour number density as function of the distance from the lidar system can be derived.
The WALES lidar system consists of two transmitters, both based on an injection-seeded optical parametric oscillator (OPO) pumped by the second harmonic of a Q-switched, diode pumped Nd:YAG laser. Thus, WALES is capable to simultaneously emit four wavelengths, three online and one offline, in the water vapour absorption band between 935 and $936 \mathrm{~nm}$. The three online wavelengths achieve the necessary sensitivity needed for measurements over the whole range of tropospheric water vapour concentration. A complete water vapour profile of the troposphere is composed by using the information of the partly overlapping line contributions. The averaged pulse energy is $35 \mathrm{~mJ}$ with a repetition rate of $200 \mathrm{~Hz}$. The vertical resolution of the raw data is $15 \mathrm{~m}$. In addition to the $935 \mathrm{~nm}$ channel, the receiver is equipped with polarization-sensitive aerosol channels at 532 and $1064 \mathrm{~nm}$, the first one with High Spectral Resolution capabilities using an iodine filter in the detection path (Esselborn et al., 2008). This allows for collocated measurements of humidity and optical depth, as well as studies of clouds and aerosol optical properties. System parameters of the WALES system are listed in Table 2. For a detailed technical description see Wirth et al. (2009).

As the main objective of the lidar measurements during the HALO Techno-Mission was high-resolution measurements of cirrus clouds, only the strong absorption line of $935.6846 \mathrm{~nm}$ was used. For the second laser, the generation of laser radiation for the medium and weak absorbing line for mid- and lower tropospheric $\mathrm{H}_{2} \mathrm{O}$ measurements was switched off. Thus, highest possible spectral purity of the HSRL (High Spectral Resolution Lidar) channel at $532 \mathrm{~nm}$ was achieved. The vertical resolution of the measurements is $150 \mathrm{~m}$, the horizontal resolution is about $1 \mathrm{~km}(5 \mathrm{~s}$ averages). The statistical error of the water vapour retrievals is about $5 \%$. A general analysis of the systems accuracy can be found in Kiemle et al. (2008).

A further problem of water vapour concentration measurements within cirrus by DIAL arises from the high spatially inhomogeneous backscatter within the cloud leading to a possible difference in the volume probed by the on-line and off-line laser pulse. A double-pulse system would be ideal for this purpose, but we found that with the high repetition rate of WALES $(100 \mathrm{~Hz}$ i.e. $10 \mathrm{~ms}$ online/offline separation) it is possible to achieve high-quality retrievals. Only at very steep gradients does the error from the inhomogeneities exceed $5 \%$. These cases are filtered out based on a variability estimate deduced from the raw signals. At cloud boundaries the scattering changes from the elastic scattering by ice particles to the spectrally broadened Rayleigh scattering by air molecules. This so-called Rayleigh-Doppler effect is well known for narrow-band DIAL systems and corrected in the retrieval by an algorithm similar to the one described by Ansmann and Bösenberg (1987). The residual error due to this effect is estimated to be below about $2 \%$. 
Table 2. System parameters of WALES.

\begin{tabular}{ll}
\hline Transmitter type & Nd:YAG laser-pumped OPO \\
\hline Pulse energy $(\mathrm{mJ})$ & 40 \\
Repetition rate $(\mathrm{Hz})$ & 200 \\
Wavelength $(\mathrm{nm})$ & $532,935,1064$ \\
Strong absorbing line $(\mathrm{nm})$ & 935.6846 \\
Medium absorbing line $(\mathrm{nm})$ & 935.6083 \\
Weak absorbing line $(\mathrm{nm})$ & 935.5612 \\
Telescope diameter $(\mathrm{cm})$ & 48 \\
Vertical resolution $(\mathrm{m})$ & 150 \\
Horizontal resolution $(\mathrm{km})$ & $1(5 \mathrm{~s})$ \\
\hline
\end{tabular}

\subsection{WARAN hygrometer}

The airborne in situ hygrometer instrument WARAN consists of a commercial tunable diode laser (TDL) device (WVSSII, Spectrasensors Inc.; Voigt et al., 2014) in combination with a Rosemount inlet system. The WVSS-II is a closedcell TDL system in which a diode laser is tuned continuously over the water vapour absorption line at $1.37 \mu \mathrm{m}$. After passing the measurement cell twice $(\sim 24 \mathrm{~cm})$, the laser intensity is measured by a photodiode. High sensitivity is achieved by utilizing second-harmonic detection as e.g. described by May and Webster (1993). The measurement range is from 30 to $40000 \mathrm{ppmv}$ covering typical atmospheric mixing ratios from ground up to the upper troposphere. The relative uncertainty increases towards lower water vapour mixing ratios from $5 \%$ above 200 ppmv up to $20 \%$ at 30 ppmv, confirmed by a direct intercomparison with calibrated data from water vapour mass spectrometer (Kaufmann et al., 2014). The air flows passively through the measurement cell. A heated Rosemount inlet system was used in order to avoid particles, especially ice crystals, entering the inlet line. While the particle separation works well for typical cirrus conditions with low number concentrations and ice particle sizes of several $10 \mu \mathrm{m}$, particles smaller than around $1 \mu \mathrm{m}$ may enter the inlet and evaporate. In combination with high number concentrations as present in e.g. mixed phase clouds or contrails, this effect can have an influence on the in-cloud humidity measurements.

\section{Results}

\subsection{Overview}

At the time of the observation (12:00 UTC) on 4 November 2010, the synoptic situation over Europe was characterized by a large-scale ridge. Cirrus clouds at upper levels are advected towards Germany within the anticyclonic jet stream (see increased values of relative humidity at $250 \mathrm{hPa}$ in Fig. 2a). Figure 2b shows the flight track of HALO between 10:21 and 13:32 UTC in the TRA Allgäu in southern

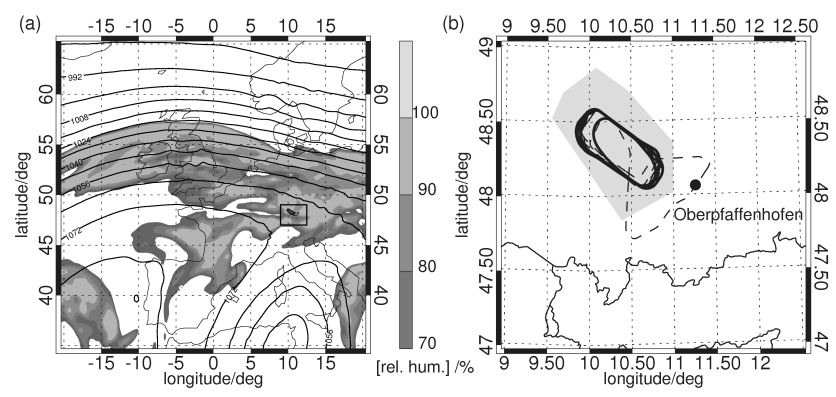

Figure 2. (a) ECMWF analysis of geopotential height (in dm, black contour lines) and relative humidity (\%, grey shading) at $250 \mathrm{hPa}$ valid on 12:00 UTC 4 November 2010. (b) Flight track of HALO between 10:46 and 13:32 UTC (dashed line). The thick black line in (b) indicated the section shown in Fig. 3. Grey area in (b) shows the TRA Allgäu. Black rectangle in (a) indicates the section shown in (b).

Germany. In the following we only consider data from the $910 \mathrm{~km}$ long section of the five consecutive oval flights between 10:47 and 11:54 UTC (solid line) when measurements were performed at constant flight level of about $14 \mathrm{~km}$. After 11:54 UTC HALO started to descend.

Figure $3 \mathrm{a}$ presents the lidar backscatter ratio cross section at $532 \mathrm{~nm}$, the ECMWF cloud ice water content, and the flight altitude of the Falcon within the cirrus cloud. The backscatter ratio indicates the cirrus cloud with a base altitude at about $10 \mathrm{~km}$ and the cirrus cloud top at about $13 \mathrm{~km}$. The backscatter ratio within the cirrus cloud shows a wide range of values from about 4 up to more than 50. Unfortunately, we were not able to reach the maximum cruise altitude of HALO during this case study to obtain an optimal distance to the cirrus cloud top to avoid signal overload (identified by the white areas in the upper part of the cloud in Fig. 3a). The comparison of the backscatter ratio and the ECMWF cloud ice water content indicates that model data and observation of cloud height and location are in good agreement, a crucial requirement to combine model data and lidar measurements. The Falcon flight track reaches the cloud at constant height level at about $11 \mathrm{~km}$ at 11:25 UTC and both aircraft flew in short horizontal distance until 11:54 UTC. This time period corresponds to a flight distance of about $220 \mathrm{~km}$. Falcon in situ measurements during that period can be used for validation of the lidar measurements and comparisons of model data within the cloud. Figure $3 \mathrm{~b}$ shows the lidar-derived upper level $(9-13 \mathrm{~km})$ optical depth (OD) at $532 \mathrm{~nm}$, which is a measure of the attenuation of light on its way through the atmosphere. The OD was determined with the high spectral resolution lidar method (Esselborn et al., 2008). It ranges between about 0.1 and 1.5 in the upper level with a very variable structure. The uncertainty of the OD in this optically rather thick cirrus cloud is about $5 \%$.

Figure $4 \mathrm{a}$ shows water vapour in situ measurements from the WARAN onboard the Falcon and remote sensing 

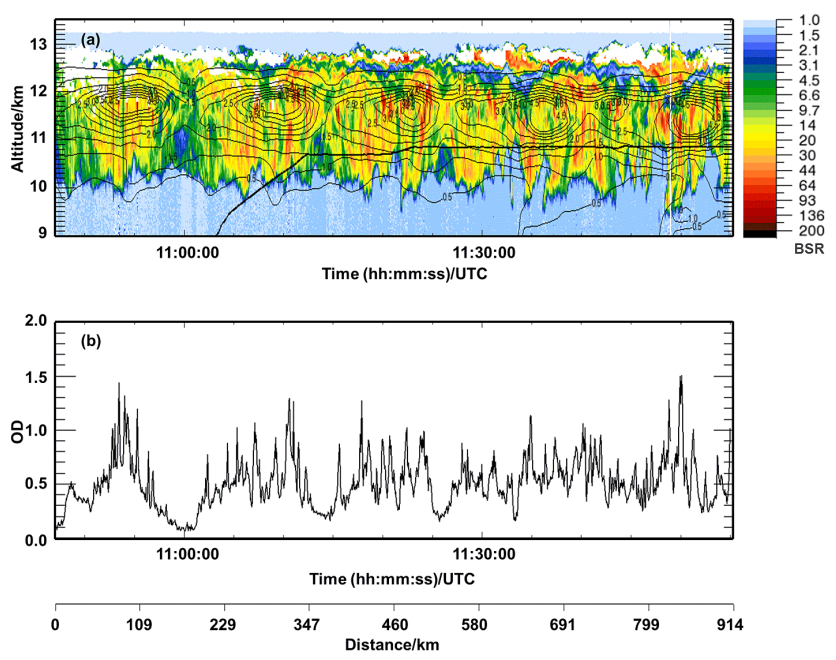

Figure 3. (a) Backscatter ratio at $532 \mathrm{~nm}$ (colour shading) between 10:47 and 11:54 UTC on 4 November 2010. White areas are caused by saturation of the detection optics. The thick black solid line indicates the altitude of the DLR Falcon; the black contour lines show the ECMWF cloud ice water content of $0.5-4.5 \mathrm{mg} \mathrm{kg}^{-1}$. (b) Optical depth (OD) at $532 \mathrm{~nm}$ of the cirrus cloud derived from WALES measurements.

observations at the same altitude and location by the DIAL WALES. In Fig. $4 \mathrm{~b}$ the horizontal distance between HALO and Falcon is plotted. The blue line (Fig. 4a, b) indicates the time when the Falcon reached a constant flight altitude of about $10.8 \mathrm{~km}$. Both measurements agree well when the distance between both measurements is less than $10 \mathrm{~km}$ (after $\sim$ 11:20 UTC). The mixing ratio during the selected time period is about 100 ppmv. Even small-scale features can be resolved well by the WALES-DIAL measurement.

\subsection{Relative importance of temperature and humidity for the determination of RHi}

Additionally to the water vapour measurements, the calculation of RHi requires collocated temperature information. As there was no remote measurement of the temperature field beneath HALO, 3-D temperature fields provided by the ECMWF global model were used. Analyses and short-term forecast with a 1-hourly temporal resolution and a T799L91 spatial resolution, i.e. $\sim 25 \mathrm{~km}$ horizontal distance between neighbouring grid points, are interpolated in space and time to match with the position of the WALES measurement (see Schäfler et al., 2010). Beside temperature, also simulated cloud ice water content and water vapour mixing ratios were interpolated to the flight track. The vertical resolution of the terrain-following model at cirrus altitude $(\sim 10-13 \mathrm{~km})$ is about $400 \mathrm{~m}$.

To estimate the accuracy of the ECMWF model temperature inside cirrus clouds and its applicability for RHi studies we compare the ECMWF temperature data with in situ
Table 3. Mean values and relative variability (averaged between 11:25 and 11:54 UTC) along Falcon flight path on 4 November 2010. For the ECMWF relative humidity uncorrected model temperature data are used. In situ relative humidity is determined from WARAN water vapour measurements and in situ temperature measurements onboard the Falcon.

\begin{tabular}{lrrrr}
\hline & \multicolumn{2}{c}{ Mean } & \multicolumn{2}{c}{ Variability } \\
\hline & ECMWF & In situ & ECMWF & In situ \\
\hline Temperature (K) & 219 & 220 & 0.0003 & 0.0006 \\
$\mathrm{H}_{2} \mathrm{O}$ mix (ppmv) & 100 & 99 & 0.03 & 0.12 \\
RHi (\%) & 103 & 91 & 0.03 & 0.12 \\
\hline
\end{tabular}

temperature measurements of the Falcon flying in the cirrus cloud beneath HALO. For this purpose, a flight path in which the Falcon flight level of about $10.8 \mathrm{~km}$ varied by less than $100 \mathrm{~m}$ (11:25-11:54 UTC) was chosen, to avoid uncertainties resulting from sharp vertical temperature gradients at changing flight altitudes.

Figure 5 presents the comparison of the Falcon in situ measurements and the ECMWF temperature (Fig. 5a), water vapour mixing ratio (Fig. $5 \mathrm{~b}$ ) and derived relative humidity (Fig. 5c). The ECMWF temperature is almost constantly colder than the in situ measurements with mean values of $\sim 219.1 \mathrm{~K}$ from ECMWF model analysis and $\sim 220.0 \mathrm{~K}$ from Falcon in situ measurements. The mean temperature difference between Falcon measurement and ECMWF in the considered height level is about $-0.9 \mathrm{~K}$. The mean value of the water vapour mixing ratio (Fig. 5b) agrees well in the considered time series with mean values of $\sim 100 \mathrm{ppmv}$ from model analysis and $\sim 99 \mathrm{ppmv}$ from WARAN in situ measurements; however, the standard deviation of the mean shows differences between both data sets (Table 3). The calculated relative humidity (Fig. 5c) differs by about $11 \%$ ( $\sim 103 \%$ using ECMWF data and $\sim 91 \%$ using in situ observations of temperature and water vapour) due to a bias in temperature data (Table 3). Additionally, RHi is calculated with WARAN water vapour measurements and ECMWF model temperatures, showing higher RHi values (Fig. 5c) which is due to the lower modelled temperatures. Figure 5 further shows that the local variability of the relative humidity is mainly caused by fluctuations in the water vapour mixing ratio. Temperature fluctuations have a minor influence on the local variability of RHi within the observed cirrus cloud.

This is also visible regarding the relative variability, which is the ratio of the standard deviation and the mean, of the temperature, the water vapour mixing ratio, and the RHi data within the considered time period. The relative variability of both temperature data sets is similar. In contrast, the distributions of mixing ratio and RHi differ significantly between model analysis and in situ measurements. The relative variability of mixing ratio and RHi are considerably larger than for the temperature, and differ by a factor of around 4 , with 


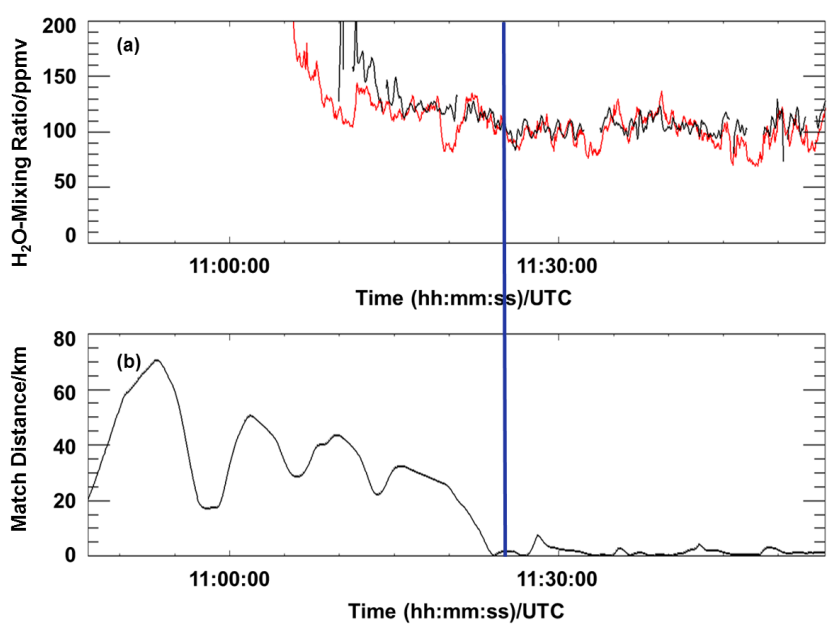

Figure 4. (a) Water vapour mixing ratio as retrieved by the WARAN instrument flown on the Falcon (red line) and the WALES instrument (black line) at the same altitude. (b) Horizontal distance between the two aircraft as a function of time.

ECMWF showing less variation than in situ data. The relative variability of the individual variables is listed in Table 3 .

The influence of temperature variability on the variability of relative humidity over ice is further estimated along the Falcon flight section (see Fig. 5) by comparing RHi values calculated with the mixing ratio from WARAN and different temperatures. The relative variability of relative humidity calculated with the Falcon temperature measurements is 0.12, with the uncorrected temperature from ECMWF analysis is 0.13 , and with a constant temperature (i.e. the mean of the Falcon measurements) is 0.12 . Values differ only by about $10 \%$, meaning that the major part of local RHi fluctuations is caused by local variations in the water vapour mixing ratio. Temperature variations give only a minor local contribution.

It is worthwhile mentioning that the ECMWF model predicts the cloud where it is detected by lidar. However, additional uncertainties in the absolute values of RHi resulting from differences in model temperature and actual temperature have to be taken into account.

\subsection{Relative humidity over ice within cirrus cloud}

To derive RHi using WALES water vapour measurements, ECMWF temperature data were interpolated in space and time to match with the measured field. Figure 5 showed differences between observed and modelled temperatures at the flight altitude of the Falcon. To verify the applicability of the model temperature in this altitude range, we compare the vertical profile of different measurements: radiosonde data from the 12:00 UTC ascents over Munich and Stuttgart, ECMWF temperature analysis data at 12:00 UTC, and HALO and Falcon profiles derived from the total air temperature sensors of both aircraft during descent to Oberpfaffenhofen (11:57 to
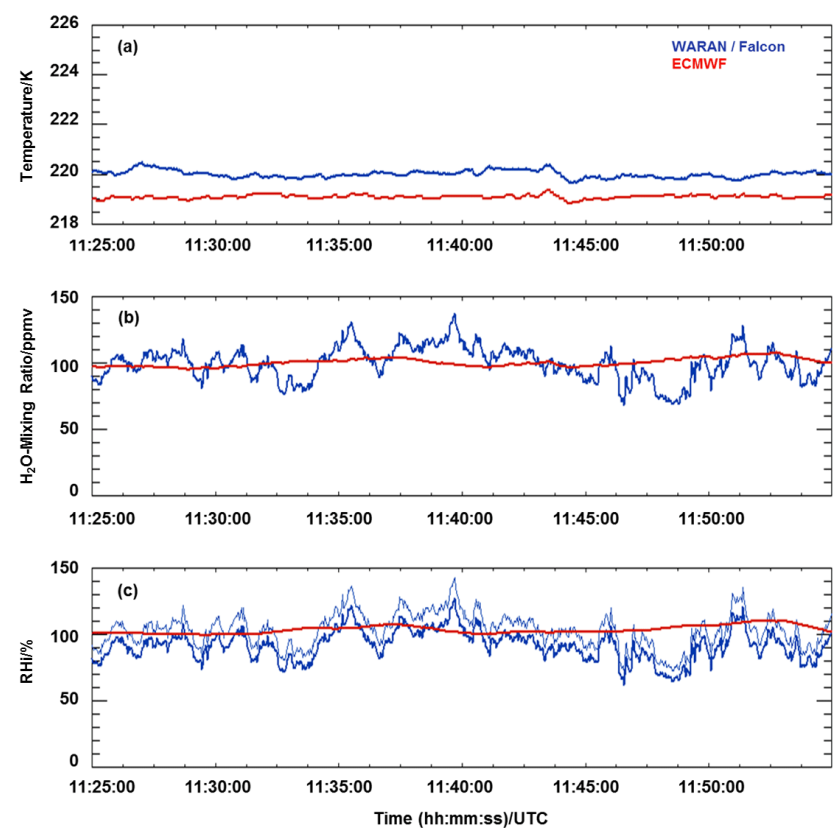

Figure 5. Comparison of in situ temperature, water vapour and RHi measurements on 4 November 2010 from WARAN onboard the Falcon (blue lines) with data from ECMWF model analysis (red lines). (a) Static air temperature, (b) water vapour mixing ratio and (c) relative humidity over ice along the flight track. The red line shows RHi calculated from ECMWF temperature and water vapour data, the thick blue line shows RHi calculated from WARAN water vapour mixing ratio and Falcon in situ temperature measurements, and the thin blue line shows RHi calculated from WARAN water vapour mixing ratio measurements and ECMWF model temperature.

13:32 UTC for HALO and 12:13 to 13:29 UTC for the Falcon) airport which is closest in time (Fig. 6).

As can readily be seen from Fig. 6a, the temperature profiles of the two radiosonde temperature profiles of Munich and Stuttgart agree well (with minor deviations between 12 and $13 \mathrm{~km}$, i.e. the tropopause region) which indicates little horizontal variability of the temperature field. This is also confirmed by horizontal sections of ECMWF temperature at $10 \mathrm{~km}$ altitude (not shown). This is important as the location of the aircraft measurements lies in between both stations. Another important result of this comparison is that the tropopause region between 12 and $13 \mathrm{~km}$ altitude is captured well in the model data, confirming that model data are appropriate to use in this altitude range. Also, the temperature profiles from the two aircraft show very comparable results up to the maximum ceiling altitude of the Falcon which is not surprising since both aircraft use the same type of total air temperature sensors (Stickney et al., 1994).

However, differences between the model temperature profile and the temperature profile measured onboard the aircraft descents can be seen (Fig. 6b). Between 9 and $11 \mathrm{~km}$ altitude, model and HALO temperature differ nearly height independently by about $0.8 \mathrm{~K}\left(T_{\mathrm{HALO}}-T_{\mathrm{ECMWF}}\right)$, whereas 


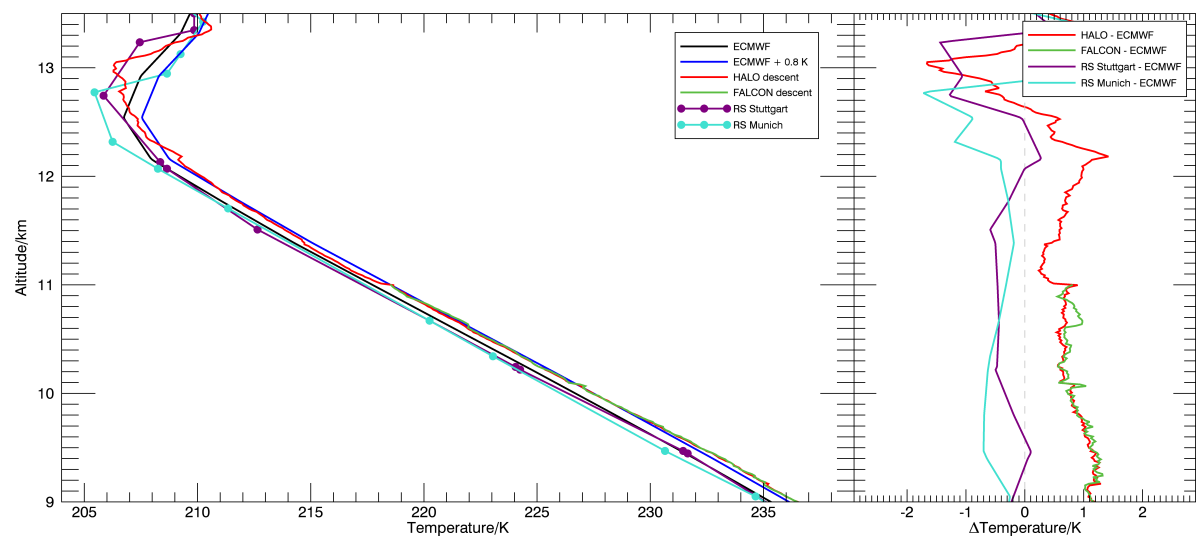

Figure 6. (a) Temperature measurements from radiosondes over Munich (light blue line) and Stuttgart (purple line) at 12:00 UTC, 4 November 2010, ECMWF model analysis (black line) and in situ measurements from HALO (red line) and Falcon (green line) descents. (b) Difference of ECMWF model analysis temperature data and HALO in situ temperature measurements (red line), Falcon in situ measurements (green line) during descents, and radiosonde temperature measurements over Munich (light blue line) and Stuttgart (purple line).

in the upper cloud region (11-13 km altitude) the difference is height dependent and varies between $-1.4 \mathrm{~K}$ (uppermost level) and about $1.5 \mathrm{~K}$ (about $12.2 \mathrm{~km}$ ). The mean difference in this height range is about $0.6 \mathrm{~K}$. In the entire altitude range $(9-13 \mathrm{~km})$ the mean difference is about $0.8 \mathrm{~K}$. The sources of the differences between model and HALO temperature are not entirely clear, although up to altitudes where both radiosondes agree very well $(\sim 12 \mathrm{~km})$ the deviation is still within the combined error that is given in the literature $\sim 0.3 \mathrm{~K}$ for radiosondes at daytime (Nash et al., 2011) and $\sim 0.5 \mathrm{~K}$ for the aircraft temperature sensors (A. Giez, personal communication, 2014; Stickney et al., 1994). Possible reasons may be uncertainties in the temperature measurements of the aircraft due to insufficient correction for flight performance parameters (A. Giez, personal communication 2014), due to radiation or cloud effects (Nash et al., 2011), or due to resolution artefacts. Comparing radiosonde temperature measurements to model and airborne temperature data we see that model and radiosondes occasionally show good agreements while airborne and radiosonde temperature measurements show similar differences to model and airborne data. To create the analysis fields, preferably the most realistic representation of the state of the atmosphere, ECMWF assimilates a multitude of different observation types, e.g. from surface stations, satellites and also radiosondes. This can explain the smaller deviations between modelled temperatures and the radiosonde profiles and may also impact on the deviations between model and aircraft data.

Although the uncertainties of the temperature measurements lead to a relative uncertainty of about $10-15 \%$ in the retrieved RHi in the considered temperature range, we conclude that the ECMWF model temperature field is suited for this kind of study.

In our case we used the available observed temperature profile of HALO to offset the ECMWF temperature field with
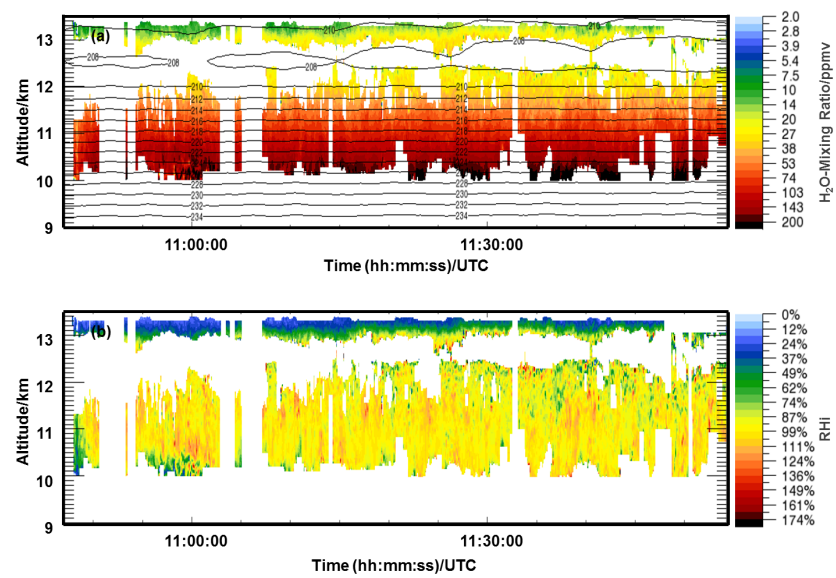

Figure 7. (a) Water vapour volume mixing ratio as measured with WALES on HALO and contour lines of ECMWF temperature. (b) Relative humidity over ice from combined WALES and ECMWF data. In the white areas no trustworthy measurements are available due to signal overload and strong variability.

a vertically constant temperature bias (of $0.8 \mathrm{~K}$ ) in the altitude range between 10 and $13 \mathrm{~km}$. For the calculation of RHi (from WALES and ECMWF data), the Goff-Gratch formula (Goff and Gratch, 1946) was used to determine the saturation pressure over ice. The cross section of water vapour mixing ratio (in combination with the model temperature field) and relative humidity over ice inside the cirrus cloud is shown in Fig. 7. The ECMWF model temperature shows low temporal variability (Fig. 7a). Considering the water vapour DIAL measurements the high intensity of the backscattered signal at about $12.5 \mathrm{~km}$ causes data gaps. Beneath $12.5 \mathrm{~km}$ the water vapour mixing ratio increases from $\sim 25 \times 10^{-6}$ to $\sim 150 \times 10^{-6}$ at the cloud base. Below $10 \mathrm{~km}$ altitude no data are available due to the low backscatter in the cloud-free air 


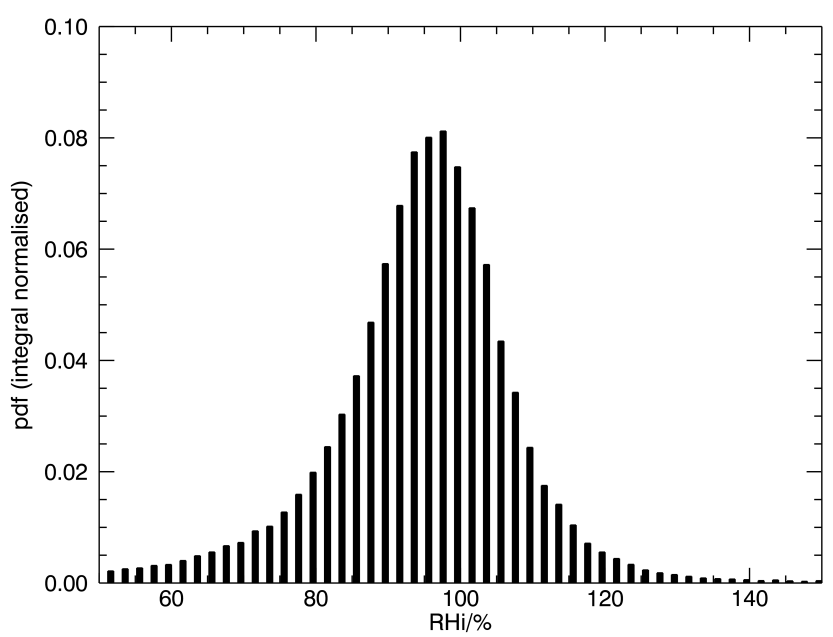

Figure 8. Frequency distribution of the relative humidity over ice inside the cirrus cloud shown in Figs. 3 and 7. The bin size of the histogram is $2 \%$.

and due to the light extinction within the cloud. In contrast to the water vapour profiles, the RHi field (Fig. 7b) depicts vertical uniformly distributed values.

The threshold for the decision whether a data point is inside the cirrus or not was set to an empirical value of 4 for the backscatter ratio (BSR) at $532 \mathrm{~nm}$. A BSR threshold of 2 did not show significant differences. A histogram of the observed relative humidity over ice within the fully developed cirrus cloud (BSC > 4) is shown in Fig. 8. The frequency distribution of RHi over the whole cirrus cloud shows a nearly Gaussian distribution with a maximum at approximately ice saturation. About $30 \%$ of all data points inside the cirrus cloud show RHi values above ice saturation; only $2 \%$ of all data points are higher than $120 \%$.

To determine a possible altitude dependence of RHi within the cirrus cloud, the cloud was divided into vertical layers with a depth of $500 \mathrm{~m}$ (see Fig. 9). Between 10 and $12 \mathrm{~km}$ no significant difference in the frequency distribution of RHi can be seen relative to the complete spectrum (Fig. 9). Only in the upper layers are small differences visible. The uppermost layer shows a shift to lower RHi values compared to the layers below with a maximum at $91 \%$ RHi.

To obtain information about the cirrus cloud life cycle we perform a correlation analysis using the 2-D RHi and backscatter ratio fields. For this analysis the backscatter and relative humidity data were interpolated to the same timeheight resolution. For studying the RHi conditions inside and outside the cirrus cloud in different cloud regimes, the presented persistent cirrus cloud observed on 4 November (discussed above) is compared with a transient/intermittent cirrus cloud drifting out of the observation area followed by cloud-free air on 3 November 2010. In this case we had the opportunity to study cloudy and cloud-free areas. Figure 10 shows the joint distribution of backscatter ratio and relative

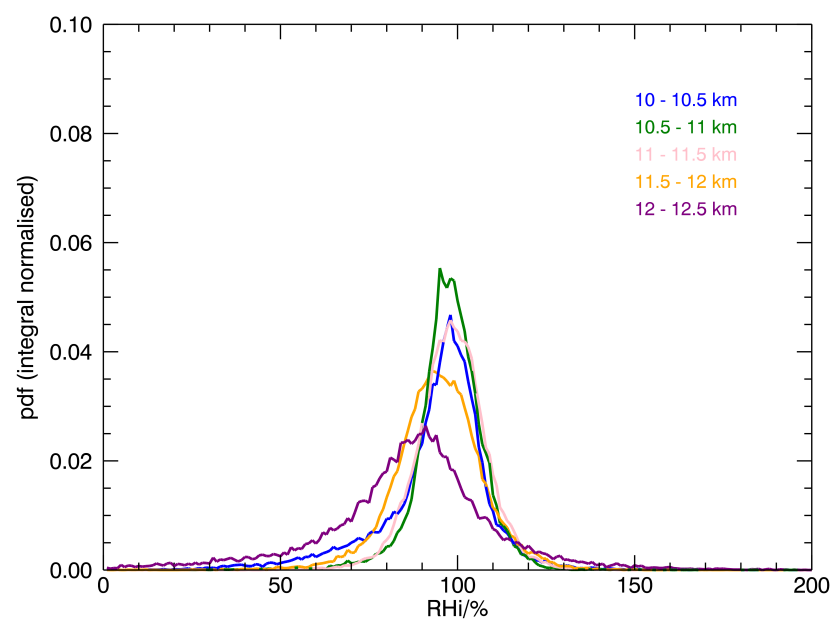

Figure 9. Frequency distribution of the relative humidity over ice at different vertical layers inside the cirrus cloud shown in Figs. 3 and 7 .

humidity over ice for both cirrus regimes. In the persistent cirrus cloud on 4 November 2010 (Fig. 10a) only very few RHi values exceed $120 \%$, even outside the cirrus at low backscatter ratios. In contrast, in the transient cirrus case (Fig. 10b) high RHi values up to $150 \%$ are found outside the cirrus cloud. In both cases, the corresponding RHi value of the maximum backscatter ratio is about $100 \%$.

\section{Summary and discussion}

We used combined airborne water vapour lidar measurements and ECMWF temperature data to analyse RHi within a cirrus cloud observed on 4 November 2010. For this analysis it is important that the model is able to reproduce the general cloud situation, as otherwise uncertainties may occur mainly due to temperature differences. For the examined case, on 4 November 2010, we therefore verified that the model is able to reproduce the cloud situation in terms of location and vertical extent of the cirrus cloud. This ensures comparability of observed and modelled cloud properties.

Considering RHi within the cirrus cloud, we experimentally found that about $30 \%$ of all data points showed supersaturation; but only $2 \%$ of all data points showed higher values than $120 \%$. This is in good agreement with former findings of about $30 \%$ ice supersaturation within mid-latitude cirrus clouds over the Southern Great Plains from combined Raman lidar measurements (Comstock et al., 2004) and from in situ measurements in the vicinity of Ireland (Ovarlez et al., 2002) during INCA (INter hemispheric difference in Cirrus properties from Anthropogenic emissions), respectively. The small differences in the observed fraction of supersaturated data points may be explained by an absolute error of about $10-15 \%$ in the RHi data, resulting mainly from uncertainties in the used temperature, as well as from differences of the 


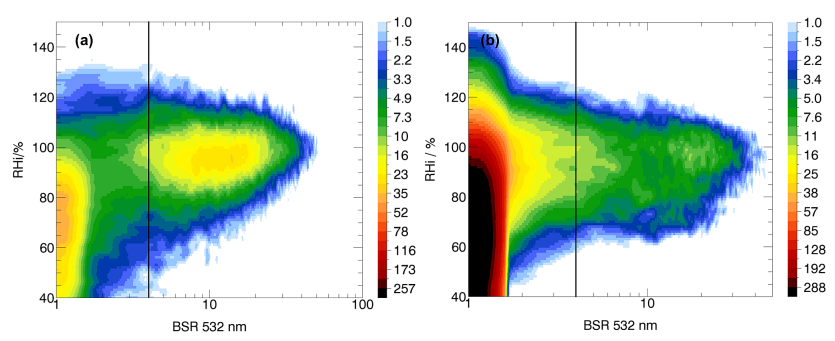

Figure 10. Histogram of the joint occurrence of the relative humidity over ice (RHi) and the extinction corrected backscatter ratio (BSR) at $532 \mathrm{~nm}$ (a) for a fully developed cirrus cloud on 4 November 2010 and (b) for a transient cirrus cloud on 3 November 2010.

evolution stage of the examined cirrus cloud regimes. Considering the INCA data set, Ovarlez et al. (2002) found that two types of distributions can be fitted to the observations; a Gaussian distribution for warm cirrus clouds $\left(T>-40^{\circ} \mathrm{C}\right)$, and a Rayleigh distribution to cirrus clouds colder than $-40^{\circ} \mathrm{C}$. The dependence of the RHi distribution on the temperature is interpreted as an effect of the length of time a cirrus cloud needs from formation to a mature equilibrium state (Spichtinger et al., 2004). Thus, the tail towards higher RHi values might be a signature of clouds that have not yet reached values close to equilibrium. The RHi distribution within the cirrus cloud of 4 November 2010 shows a nearly Gaussian distribution at a temperature range of about -45 to $-65^{\circ} \mathrm{C}$. We therefore conclude that the observed cloud is fully developed, potentially with a tendency to dissolve.

The comparison of the vertical RHi structure shows a shift to lower values in the uppermost cirrus cloud layer compared to the lower and middle part of the cloud. This is in contrast to former model studies (Khvorostyanov and Sassen, 1998a, b) indicating the region of highest ice supersaturation in the middle part of the cloud layer, the so-called ice crystal growth region, and lower ice supersaturation in the upper and lower layers with lowest ice supersaturation in the lowest layer. From ground-based Raman lidar measurements in combination with model temperature data (Comstock et al., 2004) a relatively similar frequency distribution in the upper $75 \%$ of the cloud with a high fraction of ice supersaturation was found, while in the lowermost $25 \%$ of the cloud $84 \%$ of the data points were below ice supersaturation. These findings are in good agreement with model simulations of Heymsfield and Miloshevich (1995), which showed enhanced ice supersaturation in the uppermost cloud layer and a sublimation region near the cloud base. It has to be kept in mind that we consider only a single case study in our analysis and, as mentioned above, the comparability of this case study with former findings is limited by the evolution state of the observed cloud as well as by ambient conditions. Similar to earlier findings of a positive skewness in cold clouds (Ovarlez et al., 2002), Spichtinger et al. (2004) found asymmetric RHi distributions in the upper (and colder) cloud layers based on the MOZAIC (Measurement of Ozone by Airbus In-service aircraft project) data set. They interpret their findings with the influence of vertical motion on the duration of the transition to equilibrium (Gierens, 2003) and therewith on the distribution of (super-)saturation within the cloud. As we assume the observed cloud of 4 November 2010 to be in equilibrium with a tendency to dissolve, this may explain the differences in the observed vertical RHi structure.

By comparing the relative humidity inside and outside the cirrus clouds for the fully developed stage on 4 November 2010 we found a limit of RHi values of about $120 \%$ inside as well as outside the cloud. This supports the assumption that the cloud is rather stable, maybe with a tendency to evaporate at that stage. High RHi values of approximately 140-150\% RHi are needed for homogeneous ice nucleation (DeMott et al., 1998; Koop et al., 2000; Haag et al., 2003; Kärcher, 2012). Thus the high RHi values of up to $150 \%$ following the transient cirrus cloud on 3 November 2010 suggest that homogeneous ice nucleation may play a role in cirrus cloud formation in this situation. The relative humidity corresponding to the maximum backscatter ratio was $\sim 100 \%$ in both cases. We interpret that in the centre of the cirrus, where particle density causes high backscatter ratios, the water uptake by, and evaporation of, ice crystals is in equilibrium. As expected, in both cases the RHi range is much wider outside the cirrus than within.

The presented novel analysis technique enables us to classify the evolution stage in the life cycle of the cirrus cloud as it provides information of the RHi distribution shape within the cirrus cloud, the vertical structure of the $\mathrm{RHi}$, and the joint distribution of in-cloud and out-of-cloud RHi values. As these parameters are (amongst others) dependent on the life cycle of the cloud, the novel analysis technique can give indications of whether the cloud is in a formation or dissipation stage. However, additional observations of different cloud regimes and environmental conditions are required for a thorough analysis.

\section{Conclusions}

WALES measurements during the HALO Techno-Mission show the great potential of observing water vapour with a DIAL on board the high-altitude aircraft HALO for cirrus cloud studies. The extended vertical range of the HALO aircraft makes it possible to keep a required distance of about $2 \mathrm{~km}$ to the cloud top to avoid overload of the detectors and data acquisition and maintain sufficient sensitivity at the same time. Comparisons with in situ measurements of humidity on the research aircraft Falcon flying inside the cirrus cloud confirmed the high accuracy of the WALES system. The presented study shows the advantages of lidar cross sections to provide additional information about the vertical structure of the humidity field compared to in situ 
measurements. The profile data make it possible to perform simultaneous statistical analysis in different cloud layers.

Since the Techno-Mission was focused mainly on the technical performance of aircraft and instruments, it is beyond the scope of this study to address all details of cirrus cloud formation to its full extent. The flights were limited with respect to the operation area and to local meteorological conditions. For the future, additional data are required during the entire life cycle of a cirrus cloud. Future HALO missions, especially the ML-Cirrus mission, are focusing on this topic and will benefit from the findings and techniques presented in this article. The measurement of temperature profiles with a microwave temperature profiler, as planned for the ML-Cirrus mission, will enable elaboration of the presented methods.

Acknowledgements. This work has been funded by the Deutsche Forschungsgemeinschaft (DFG) in the SPP (no. 1294/2) "Atmosphären- und Erdsystemforschung mit dem Forschungsflugzeug HALO (High Altitude and Long Range Research Aircraft)" and under contract no. KI1567/1-1 and no. VO1504/21. S. Kaufmann was funded by the Helmholtz-Gemeinschaft Deutscher Forschungszentren e.V. (HGF) under contract VH-NG309 within the Helmholtz-Hochschul Young Investigators group AEROTROP. The authors like to thank the staff members of the DLR Falcon and the HALO aircraft from DLR Flight Experiments for preparing and performing the measurement flights and providing Falcon in situ temperature measurements and analysis.

The service charges for this open access publication have been covered by a Research Centre of the Helmholtz Association.

Edited by: M. Hamilton

\section{References}

Ansmann, A. and Bösenberg J.: Correction scheme for spectral broadening by Rayleigh scattering in differential absorption lidar measurements of water vapour in the troposphere, Appl. Optics, 26, 3026-3032, doi:10.1364/AO.26.003026, 1987.

Bösenberg, J.: Ground-based differential absorption lidar for watervapor and temperature profiling: Methodology, Appl. Optics, 37, 3845-3860, doi:10.1364/AO.37.003845, 1998.

Browell, E. V., Ismail, S., and Grant, W. B.: Differential absorption lidar (DIAL) measurments from air and space, Appl. Phys. B, 67, 399-410, 1998.

Chen, T., Rossow, W. B., and Zhang, Y.: Radiative effects of cloudtype variations, J. Climate, 13, 264-286, doi:10.1175/15200442(2000)013<0264:REOCTV>2.0.CO;2, 2000.

Comstock, J. M., Ackerman, T. P., and Turner, D. D.: Evidence of high ice supersaturation in cirrus clouds using ARM Raman lidar measurements, Geophys. Res. Lett., 31, L11106, doi:10.1029/2004GL019705, 2004.

Cox, S. K.: Cirrus clouds and the climate, J. Atmos. Sci., 28, 1513-1515, doi:10.1175/15200469(1971)028<1513:CCATC>2.0.CO;2, 1971.
DeMott, P. J., Rogers, D. C., Kreidenweis, S. M., Chen, Y., Twohy, C. H., Baumgardner, D., Heymsfield, A. J., and Chan, K. R.: The role of heterogeneous freezing nucleation in upper tropospheric clouds: Inferences from SUCCESS, Geophys. Res. Lett., 25, 1387-1390, doi:10.1029/97GL03779, 1998.

Ehret, G., Kiemle, C., Renger, W., and Simmet, G.: Airborne remote sensing of tropospheric water vapor with a near-infrared differential absorption lidar system, Appl. Optics., 32, 4534-4551, doi:10.1364/AO.32.004534, 1993.

Esselborn, M., Wirth, M., Fix, A., Tesche, M., and Ehret, G.: Airborne high spectral resolution lidar for measuring aerosol extinction and backscatter coefficients, Appl. Optics, 47, 346-358, doi:10.1364/AO.47.000346, 2008.

Fricke, C., Ehrlich, A., Jäkel, E., Bohn, B., Wirth, M., and Wendisch, M.: Influence of local surface albedo variability and ice crystal shape on passive remote sensing of thin cirrus, Atmos. Chem. Phys., 14, 1943-1958, doi:10.5194/acp-14-19432014, 2014.

Fusina, F., Spichtinger, P., and Lohmann, U.: Impact of ice supersaturated regions and thin cirrus on radiation in the midlatitudes, $\mathrm{J}$. Geophys. Res., 112, D24S14, doi:10.1029/2007JD008449, 2007.

Gierens, K.: On the transition between heterogeneous and homogeneous freezing, Atmos. Chem. Phys., 3, 437-446, doi:10.5194/acp-3-437-2003, 2003.

Goff, J. A. and Gratch, S.: Low-pressure properties of water from -160 to 212 F, Trans. Am. Soc. Heating Air-Cond. Eng., 52, 95122 , presented at the 52nd annual meeting of the American society of heating and ventilating engineers, New York, 1946.

$\mathrm{Gu}$, Y. and Liou, K. N.: Interactions of radiation, microphysics, and turbulence in the evolution of cirrus clouds, J. Atmos. Sci., 57, 2463-2479, doi:10.1175/15200469(2000)057<2463:IORMAT>2.0.CO;2, 2000.

Haag, W. and Kärcher, B.: The impact of aerosols and gravity waves on cirrus clouds at midlatitudes, J. Geophys. Res., 109, D12202, doi:10.1029/2004JD004579, 2004.

Haag, W., Kärcher, B., Ström, J., Minikin, A., Lohmann, U., Ovarlez, J., and Stohl, A.: Freezing thresholds and cirrus cloud formation mechanisms inferred from in situ measurements of relative humidity, Atmos. Chem. Phys., 3, 1791-1806, doi:10.5194/acp3-1791-2003, 2003.

Heymsfield, A. J.: Precipitation development in stratiform ice clouds: A microphysical and dynamical study, J. Atmos. Sci., 34, 367-381, doi:10.1175/15200469(1977)034<0367:PDISIC>2.0.CO;2, 1977.

Heymsfield, A. J. and Miloshevich, L. M.: Relative humidity and temperature influences on cirrus formation and evolution: Observations from wave clouds and FIRE II, J. Atmos. Sci., 52, 4302-4326, doi:10.1175/15200469(1995)052<4302:RHATIO>2.0.CO;2, 1995.

IPCC: Climate change 2007: The scientific basis, Cambridge University Press, 2007

IPCC: Climate change 2013: The Physical Science Basis, Cambridge University Press, 2013.

Kaufmann, S., Voigt, C., Jeßberger, P., Jurkat, T., Schlager, H., Schwarzenboeck, A., Klingebiel, M., and Thornberry, T.: In situ measurements of ice saturation in young contrails, Geophys. Res. Lett., 41, 702-709, doi:10.1002/2013GL058276, 2014. 
Kärcher, B.: Atmospheric Ice Formation Processes, in: Atmospheric Physics, edited by: Schumann, U., Research Topics in Aerospace, pp. 151-168, Springer Berlin Heidelberg, 2012.

Kärcher, B. and Lohmann, U.: A parameterization of cirrus cloud formation: Heterogeneous freezing, J. Geophys. Res., 108, 4402, doi:10.1029/2002JD003220, 2003.

Khvorostyanov, V. I. and Sassen, K.: Cirrus cloud simulation using explicit microphysics and radiation; Part I: Model description, J. Atmos. Sci., 55, 1808-1821, doi:10.1175/15200469(1998)055<1808:CCSUEM>2.0.CO;2, 1998a.

Khvorostyanov, V. I. and Sassen, K.: Cirrus cloud simulation using explicit microphysics and radiation; Part II: microphysics, vapor and ice mass budgets, and optical and radiative properties, J. Atmos. Sci., 55, 1822-1845, 1998b.

Kiemle, C., Wirth, M., Fix, A., Ehret, G., Schumann, U., Gardiner, T., Schiller, C., Sitnikov, N., and Stiller, G.: First airborne water vapor lidar measurements in the tropical upper troposphere and mid-latitudes lower stratosphere: accuracy evaluation and intercomparisons with other instruments, Atmos. Chem. Phys., 8, 5245-5261, doi:10.5194/acp-8-5245-2008, 2008.

Koop, T., Luo, B., Tsias, A., and Peter, T.: Water activity as the determinant for homogenous ice nucleation in aqueous solutions, Nature, 406, 611-614, 2000.

Krautstrunk, M. and Giez, A.: The transition from Falcon to HALO era airborne atmospheric research, in Atmospheric Physics, edited by: Schumann, U., Research Topics in Aerospace, pp. 609-624, Springer Berlin Heidelberg, 2012.

Krebsbach, M., Koppmann, R., Bühler, F., Heuser, H.-P., Knieling, P., Scheidt, M., and Spahn, H.: Measurements of Stable Carbon Isotope Ratios in Atmospheric VOC on HALO during TACTS and ESMVal, Geophys. Res. Abstr., EGU2013-3853, EGU General Assembly 2013, Vienna, Austria, 2013.

Liou, K.-N.: Light scattering by ice clouds in the visible and infrared: A theoretical study, J. Atmos. Sci., 29, 524-536, 1972.

Liou, K.-N.: Influence of cirrus clouds on weather and climate processes: a global perspective, Mon. Weather Rev., 114, 1167-1199, doi:10.1175/15200493(1986)114<1167:IOCCOW>2.0.CO;2, 1986

May, R. D. and Webster, C. R.: Data processing and calibration for tunable diode laser harmonic absorption spectrometers, J. Quant. Spectrosc. Ra., 49, 335-347, 1993.

Nash, J., Oakley, T., Vömel, H., and Wei, L. I.: WMO intercomparion of high quality radiosonde systems: Yanjiang, China, 12 July-3 August 2010, IOM Rep. 107, WMO/TD-1580, 238 pp., 2011.

Ovarlez, J., Gayet, J.-F., Gierens, K., Ström, J., Ovarlez, H., Auriol, F., Busen, R., and Schumann, U.: Water vapor measurements inside cirrus clouds in northern and southern hemispheres during INCA, Geophys. Res. Lett., 29, 1813, doi:10.1029/2001GL014440, 2002.
Roiger, A., Aufmhoff, H., Stock, P., Arnold, F., and Schlager, H.: An aircraft-borne chemical ionization - ion trap mass spectrometer (CI-ITMS) for fast PAN and PPN measurements, Atmos. Meas. Tech., 4, 173-188, doi:10.5194/amt-4-173-2011, 2011.

Schäfler, A., Dörnbrack, A., Kiemle, C., Rahm, S., and Wirth, M.: Tropospheric water vapor transport as determined from airborne lidar measurements, J. Atmos. Ocean. Tech., 27, 2017-2030, doi:10.1175/2010JTECHA1418.1, 2010.

Seifert, M., Ström, J., Krejci, R., Minikin, A., Petzold, A., Gayet, J.-F., Schlager, H., Ziereis, H., Schumann, U., and Ovarlez, J.: Aerosol-cirrus interactions: a number based phenomenon at all?, Atmos. Chem. Phys., 4, 293-305, doi:10.5194/acp-4-293-2004, 2004.

Spichtinger, P., Gierens, K., Smit, H. G. J., Ovarlez, J., and Gayet, J.-F.: On the distribution of relative humidity in cirrus clouds, Atmos. Chem. Phys., 4, 639-647, doi:10.5194/acp-4-639-2004, 2004.

Stefanutti, L., Sokolov, L., Balestri, S., MacKenzie, A. R., and Khattatov, V.: The M-55 geophysica as a platform for the airborne polar experiment, J. Atmos. Ocean. Tech., 16, 1303-1312, doi:10.1175/1520-0426(1999)016<1303:TMGAAP>2.0.CO;2, 1999.

Stephens, G. L., Tsay, S.-C., Stackhouse Jr., P. W., and Flatau, P. J.: The relevance of the microphysical and radiative properties of cirrus clouds to climate and climatic feedback, J. Atmos. Sci., 47, 1742-1754, 1990.

Stickney, T. M., Shedlov, M. W., and Thompson, D. I.: Goodrich total temperature sensors, Technical Report 5755, Rev.C, 1994.

Ström, J. and Ohlsson, S.: In situ measurements of enhanced crystal number densities in cirrus clouds caused by aircraft exhaust, J. Geophys. Res., 103, 11355-11361, doi:10.1029/98JD00807, 1998.

Voigt, C., Jeßberger, P., Jurkat, T., Kaufmann, S., Baumann, R., Schlager, H., Bobrowski, N., Guffirda, G., and Salerno, G.: Evolution of $\mathrm{SO}_{2}, \mathrm{HCl}, \mathrm{HNO}_{3}$ and $\mathrm{CO}_{2}$ in the volcanic plume from Etna, Geophys. Res. Lett., 41, 2196-2203, doi:10.1002/2013GL058974, 2014.

Wirth, M., Fix, A., Mahnke, P., Schwarzer, H., Schrandt, F., and Ehret, G.: The airborne multi-wavelength h2o-dial wales: system design and performance, Appl. Phys. B, 96, 201-213, doi:10.1007/s00340-009-3365-7, 2009. 